\title{
Comparison of different control methods applied in air conditioning systems
}

\author{
Jiao Hua ${ }^{a}$, Liu Jingyun ${ }^{b^{*}}$, Ge Chunfa \\ Logistics Department, Automation School, Beijing Union University, Beijing, 100101, China \\ aemail:wuyun_jiaohua@126.com, ${ }^{b^{*}}$ Corresponding author, email: ljy@buu.edu.cn
}

Keywords: PID, Fuzzy control, Model predictive control, A/C system, Simulation

\begin{abstract}
This paper used PID, fuzzy and model predictive control methods to control the indoor air temperature and absolute humidity of an A/C system. Simulations were carried out with the three methods in Matlab and the three methods were compared in terms of static and dynamic characteristics. Results showed that, all the three can be used in $\mathrm{A} / \mathrm{C}$ system control and the static errors were all acceptable. While the model predictive control showed the best control performance.
\end{abstract}

\section{Introduction}

Air conditioning $(\mathrm{A} / \mathrm{C})$ systems are widely used in various buildings to achieve a specified environment for living. With the improvement of people's living environment comfort requirements, both the temperature and humidity are emphasized in the $\mathrm{A} / \mathrm{C}$ system [1-2] which makes control difficult and challenging.

As presented in [3], the feedback control, artificial intelligent control, and some advanced control methods are implemented for the $\mathrm{A} / \mathrm{C}$ systems.

In the feedback control methods, the PID control algorithm has the advantages of simple structure, fast response and high precision, and becomes the most popular method [3-4]. However, PID parameters have to be selected carefully to avoid system instabilities [3]. Some intelligent methods were proposed to control the A/C systems. Servet [5] used fuzzy logic to get the proportional integral derivative parameters and realized self-tuning PID control of A/C system indoor air temperature and humidity with faster response speed and smaller steady state error.

Fuzzy logic has emerged as a superior control method for processes that are mathematically difficult to model and more complex or highly nonlinear, and that have performance limitations [5]. In terms of indoor air temperature and humidity control, M. Becker etc [6] proposed fuzzy control method for refrigeration system which had a good performance in the whole system operation range. The fuzzy control method could be considered to be applied in $\mathrm{A} / \mathrm{C}$ system. Peng etc [7] designed experience based fuzzy controller and artificial neural network compensated fuzzy controller respectively for artificial climate chest temperature and humidity control. Fuzzy logic control provides simple and effective solutions for complex A/C system control.

Among the advanced control methods, MPC is gradually becoming a major research topic. Abdul et al [8] presented that MPC was one of the most promising techniques used in HVAC systems because of its ability to integrate disturbance rejection, handle constraints, considering slow-moving dynamic control and energy conservation strategies into controller formulation.

In this paper, the traditional PID control method, a fuzzy control method and the MPC were used to control the indoor air temperature and humidity of an $\mathrm{A} / \mathrm{C}$ system and compared. Simulations were carried out and the results were analyzed.

\section{Materials and methods}

(1) A/C system model

The model used in this paper was proposed by Qi for an A/C system [9]. According to the mechanism of heat mass transfer in air conditioning system, the model was presented as follows, 
$C_{p} \_$Air specific heat, $\mathrm{kJ} \cdot \mathrm{kg}^{-1} \cdot \mathrm{K}^{-1}$

$$
\begin{gathered}
C_{p} \rho V \frac{\mathrm{d} T}{\mathrm{~d} t}=C_{p} \rho f \Delta T+Q_{\mathrm{load}}+Q_{\mathrm{spl}} \\
\rho V \frac{\mathrm{d} W}{\mathrm{~d} t}=\rho f \Delta W+M
\end{gathered}
$$

$\rho-$ Wet air density, $\mathrm{kg} \cdot \mathrm{m}^{-3}$

$V$ - Indoor air volume, $\mathrm{m}^{3}$

$T$ - Indoor air temperature, ${ }^{\circ} \mathrm{C}$

$f_{1}$ - Air volume flow, $\mathrm{m}^{3} \cdot \mathrm{s}^{-1}$

$\Delta T$-Evaporator outlet temperature and indoor temperature difference, ${ }^{\circ} \mathrm{C}$

$Q_{\text {load }}$ Indoor heat load, $\mathrm{kW}$

$Q_{\mathrm{spl}}$ - The incressing degree of fan, $\mathrm{kW}$

$W$ - Indoor air humidity, $\mathrm{kg} \cdot \mathrm{kg}^{-1}$

$\Delta W$ Evaporator outlet and indoor air humidity difference, $\mathrm{kg} \cdot \mathrm{kg}^{-1}$

$M$-Indoor humidity load, $\mathrm{kg} \cdot \mathrm{s}^{-1}$

The model is shown in Equ. (3).

$$
\left\{\begin{array}{l}
\dot{x}=A x+B u \\
y=C x
\end{array}\right.
$$

$\boldsymbol{x}$ — state variable

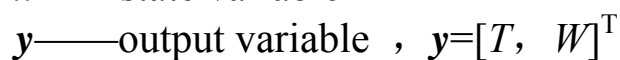

$\mathbf{u}-$ intput variable, $\boldsymbol{u}=[f, s]^{\mathrm{T}}$

$s$ - compressor speed, rpm

$f$ - fan speed, rpm

Based on this model, the controllers for PID, fuzzy control and MPC were designed. In all those controllers, the fan speed and the compressor speed were the control variables, the indoor temperature and absolute humidity were the controlled variables.

(2) Control methods

a. PID control

The control law of PID is:

$$
u(t)=k_{p}\left(e(t)+\frac{1}{T_{i}} \int_{0}^{t} e(t) d t+\frac{T_{d} d e(t)}{d t}\right)
$$

Where, $e(t)$ is the difference between the set point and the real-time value of the controlled variables in time $t ; K_{p}$ is the proportional coefficient, $T_{i}$ is the integral time constant, $T_{d}$ is the differential time constant.

The control structure of the PID method designed for the $\mathrm{A} / \mathrm{C}$ system is shown in Fig. 1. Two controllers were used, one is used to calculate the appropriate compressor speed and the other one is to get the fan speed.

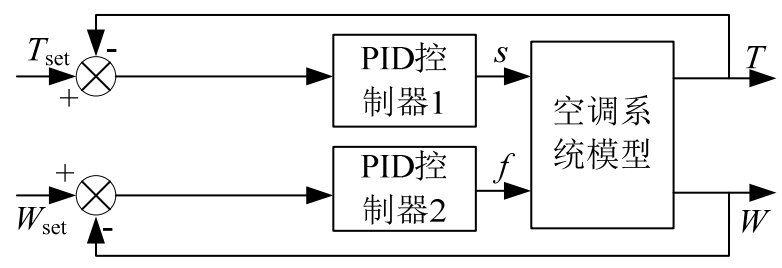

b. Fuzzy control

Fig. 1. Control structure of the PID control method.

The structure of the typical fuzzy controller is shown in Fig. 2, where two fuzzy controllers were designed. 


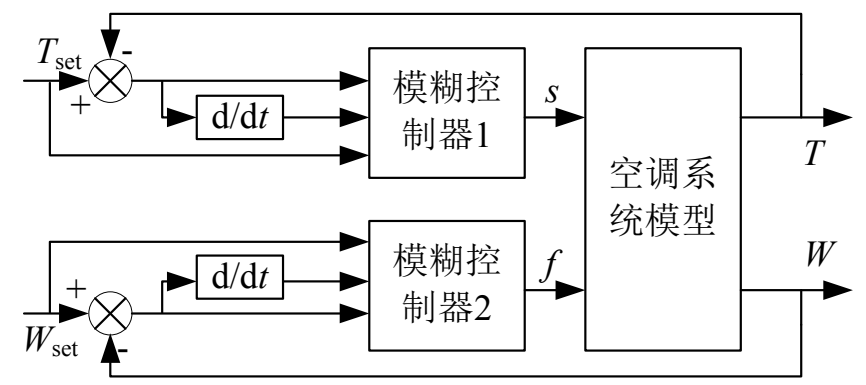

Fig. 2. Control structure of the Fuzzy control method.

After the input and output variables of the fuzzy controller are determined by the model, the spatial division of linguistic variables and the membership function of the value of the language are defined as a special kind of piecewise linear function. Seven linguistic variables were used for each input of fuzzy controllers, which were as follows: NB, NM, NS, ZO, PS, PM, PB. Take the membership function of $e_{T}$ for example, its membership function was shown in Fig. 3. The deduction rules for the fuzzy controllers were all designed.

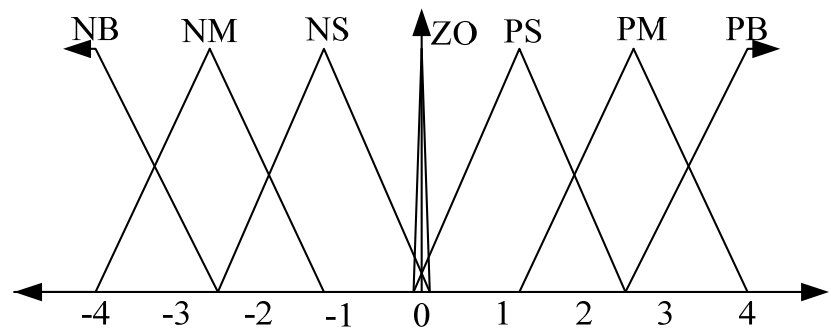

Fig. 3. Membership Function of eT

c. MPC

The MPC control structure for the A/C system was shown in Fig. 4. The model in Part 2.2 was used as the prediction model. The control cycle was the same as the prediction cycle. In the optimization process, a cost function was used to calculate the optimized control variables in the next control cycle, which was shown in Equ. (4).

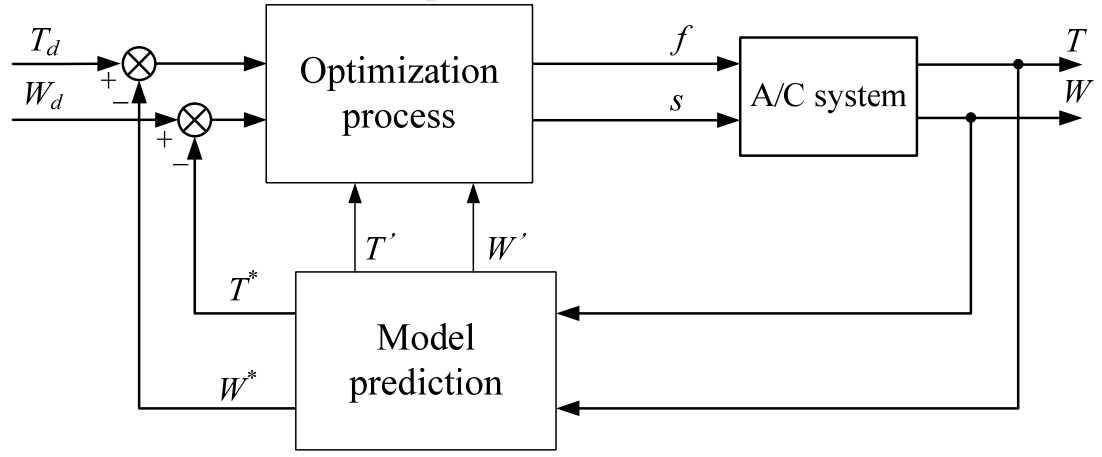

Fig. 4. Control structure of the MPC

$$
J=\alpha\left(T-T_{d}\right)^{2}+\beta\left(W-W_{d}\right)^{2}
$$

Where, $\alpha$ and $\beta$ are the weight coefficients for the indoor air temperature and absolute humidity optimization.

\section{Simulation and results analysis}

Simulations were carried out with the three control methods in Matlab. The initial indoor air temperature is $24{ }^{\circ} \mathrm{C}$ and absolute humidity is $0.0113 \mathrm{~kg} \cdot \mathrm{kg}^{-1}$. Sset points of the indoor air temperature and absolute humidity varied from 20 to $28{ }^{\circ} \mathrm{C}$ and from 0.008 to $0.013 \mathrm{~kg} \cdot \mathrm{kg}^{-1}$ respectively. The simulation results were shown in Fig. 5 6. 


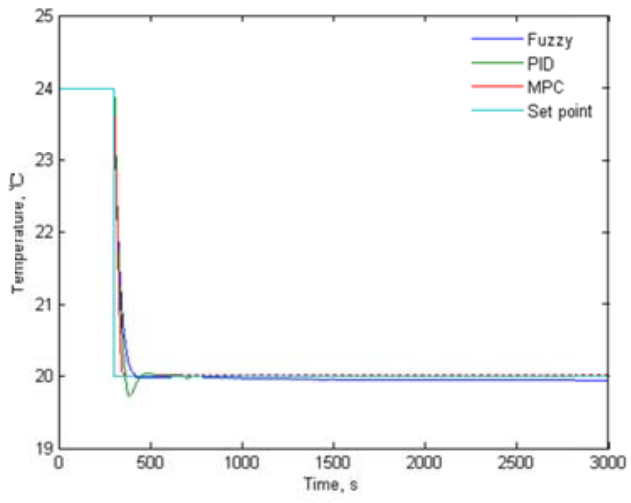

(a)

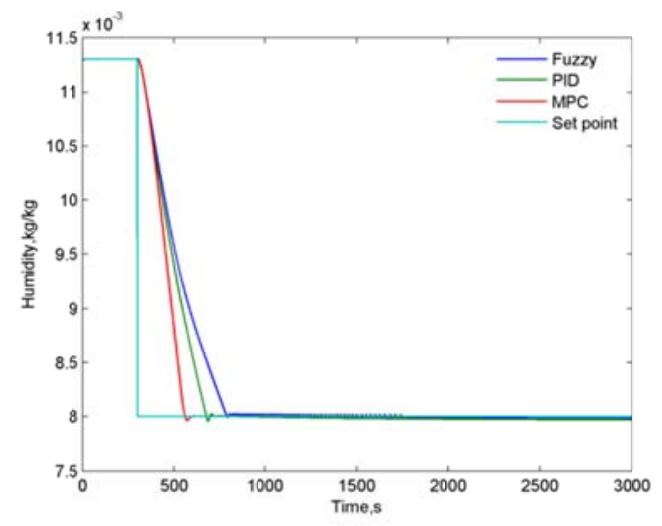

(b)

Fig. 5. Indoor air temperature and humidity change curves with the three control methods under the set points of $20^{\circ} \mathrm{C} / 0.008 \mathrm{~kg} \cdot \mathrm{kg}^{-1}$.

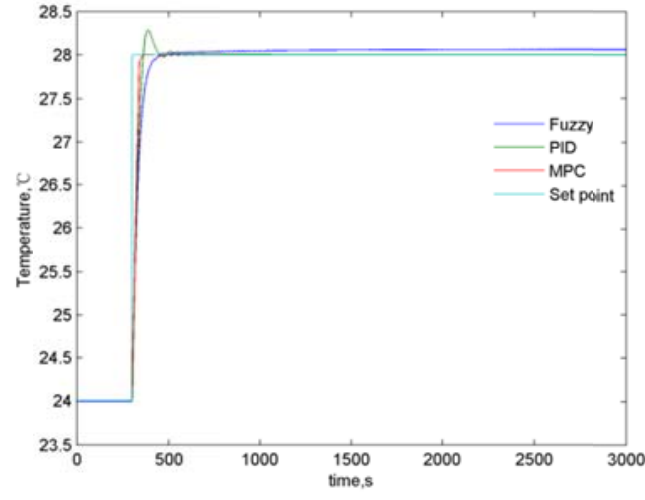

(a)

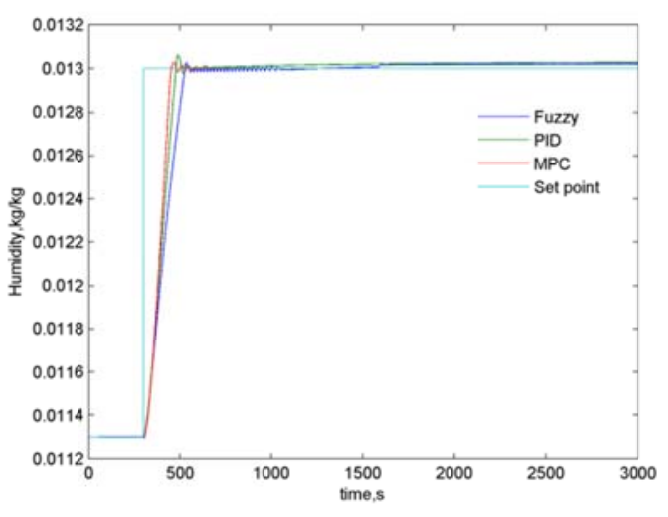

(b)

Fig. 6. Indoor air temperature and humidity change curves with the three control methods under the set points of $28^{\circ} \mathrm{C} / 0.013 \mathrm{~kg} \cdot \mathrm{kg}^{-1}$.

From the results, we can get that the three control methods all work well in the $\mathrm{A} / \mathrm{C}$ system control. The steady state errors of indoor air temperature and humidity were all within $0.5 \%$ and $1.25 \%$. The MPC presented the best dynamic characteristics in terms of control speed and oscillation. The PID control showed a quick response to the set points, while the fuzzy control had smaller overshoot than the PID method.

\section{Conclusions}

Three control methods were used to control the indoor air temperature and humidity of an $\mathrm{A} / \mathrm{C}$ system and compared. Simulations were carried out in Matlab. All the three control methods can be used in the $\mathrm{A} / \mathrm{C}$ system control. The MPC showed best control performance. PID control method is the simplest of the three control methods in terms of design and the control speed is higher than the Fuzzy control. The fuzzy control showed better steady characteristics than the PID control. The three control methods can be referred to in the A/C system control system design.

\section{Acknowledgement}

This work is supported by "New Start" Academic Research Projects of Beijing Union University (ZK10201401).

\section{References}

[1] Qi Qi, Shiming Deng. Multivariable control of indoor air temperature and humidity in a direct expansion (DX) air conditioning (A/C) system[J]. Building and Environment, 2009, 44: 1659-1667. 
[2] Krakow K. I.,Lin S.,Zeng Z. S.. Temperature and humidity control during cooling and dehumidifying by compressor and evaporator fan speed variation. ASHRAE Transactions, 1995,101(1):292-304.

[3] Liu Jingyun, Zhou Huiling, Zhou Xiaoguang, et al.Automatic air conditioning system control a survey,2011 International Conference on Electronic \& Mechanical Engineering and Information Technology, Haerbin, 2011.8

[4] Deyuan, C. Siyuan, and et al, "Research on PID control parameters tuning based on election-survey optimization algorithm," 2010 International Conference on Computing, Wuhan China, pp. 323-326, June 2010.

[5] Servet Soyguder, Mehmet Karakose, Hasan Alli, "Design and simulation of self-tuning PID-type fuzzy adaptive control for an expert HVAC system”, Expert Systems with Applications,,vol. 36, pp. 4566-4573, 2009.

[6] M. Becker, D. Oestreich, H. Hasse, et al, "Fuzzy control for temperature and humidity in refrigeration systems", Proceedings of the Third IEEE Conference on Control Applications, pp. 1607-1612, 1994.

[7] Peng Yonggang, Pang Wenrao, Luo Xiaoping, "Model design of artificial climate chest intelligent control based on Simulink", Chinese Journal of Scientific Instrument, vol. 27, No. 6, pp. 1887-1890, 2006.

[8] Abdul A., Farrokh J. S. "Theory and applications of HVAC control systems - A review of model predictive control (MPC)", Building and Environment, vol. 72, pp. 343-355, 2014.

[9] Qi Q., Deng S. "Multivariable control-oriented modeling of a direct expansion (DX) air conditioning (A/C) system", International Journal of Refrigeration, vol. 31, pp. 841-849, 2008. 